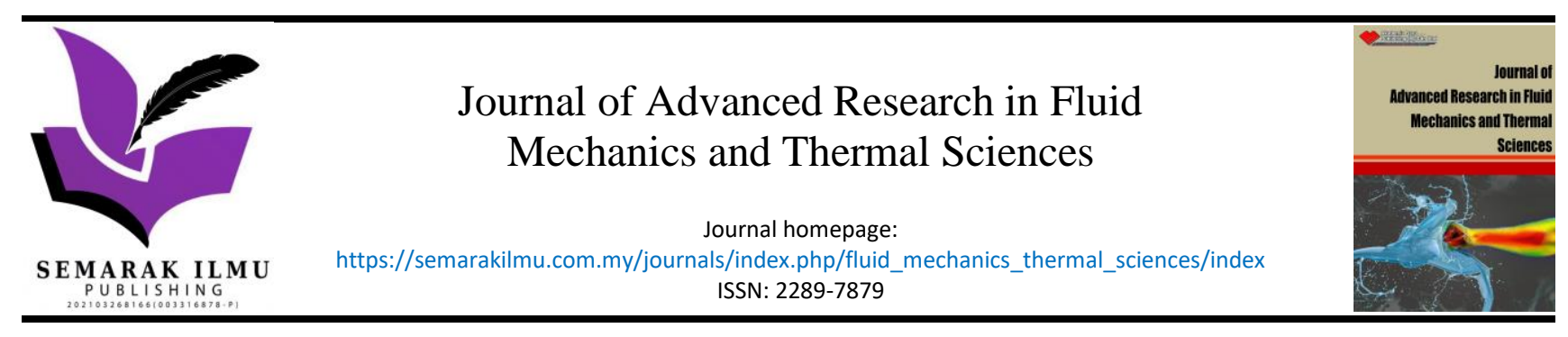

\title{
An Identification Size of The Interdigitated Flow Field on Pressure Loss Effects and Efficiencies in Vanadium Redox Flow Battery
}

\author{
Hairul Mardiah Hamzah ${ }^{1,2}$, Teo Ming Ting ${ }^{2}$, Ebrahim Abouzari-Lotf ${ }^{3}$, Roshafima Rasit Ali ${ }^{1, *}$, Saidatul \\ Sophia Sha'rani ${ }^{1}$ \\ Malaysia-Japan International Institute of Technology, Universiti Teknologi Malaysia, 54100, Kuala Lumpur, Malaysia \\ Radiation Processing Technology Division, Malaysian Nuclear Agency, Bangi, 43000, Kajang, Selangor, Malaysia \\ Helmholtz Institute Ulm (HIU) Electrochemical Energy Storage, Helmholtzstraße 11, D-89081, Ulm, Germany
}

ARTICLE INFO
ABSTRACT

\section{Article history:}

Received 24 June 2021

Received in revised form 30 September 2021

Accepted 10 October 2021

Available online 1 December 2021

\section{Keywords:}

Vanadium redox flow battery; energy storage; battery efficiency; interdigitated flow field

\begin{abstract}
In vanadium redox flow battery (VRFB), the active area for charge-discharge plays an important role on the optimization of the system. In this work, the optimum flow rate and current density of Nafion 117 membranes were examined and compared using $5 \mathrm{~cm}^{2}$ and $25 \mathrm{~cm}^{2}$ size of interdigitated flow field to operate VRFB at maximum efficiencies and discharge capacity. During discharge, flow field $25 \mathrm{~cm}^{2}$ showed the highest discharge capacity of $367.5 \mathrm{mAh}$ at $10 \mathrm{mAcm}^{-2}$ as compared to $5 \mathrm{~cm}^{2}$ flow filed which gave 221.9mAh. For battery efficiencies, three different parameters showed significant effects on different size of interdigitated flow field. $25 \mathrm{~cm}^{2}$ size of interdigitated flow field gave higher efficiencies than $5.0 \mathrm{~cm}^{2}$ up to $98 \%$. This research offers fundamental understandings that bigger active area is needed to fully utilize the performance of VRFB.
\end{abstract}

\section{Introduction}

Due to inutility of solar energy and wind energy, a storage solution such as vanadium redox flow batteries (VRFBs) are needed to store large-scale energy generation and balance the voltage fluctuations. In moderate climates, short fluctuations in solar system and their strain on the electricity grid will become extensive issue in regards to future large-scale application of photovoltaic systems [1]. Among all of redox flow batteries available, VRFBs are regarded as the high potential alternative devices for large energy storage systems. VRFBs became more attractive since 1980s due to their promising long life and low maintenance cost as compared to other redox flow batteries [24]. Recently, lithium-ion battery has jumped into safety controversy with frequent explosion incidents which indicate that lithium-ion battery is not robust and requires protection circuitry incorporated to ensure that they are kept within their safe operating limits. The vanadium electrolyte incorporated in VRFB is a nonflammable aqueous solution and has high heat capacity to restrict the temperature rise. Therefore, VRFB does not have risk of explosion and ignition [3]. The performance

\footnotetext{
* Corresponding author.

E-mail address: roshafima@utm.my

https://doi.org/10.37934/arfmts.89.2.128138
} 
of VRFB relies mostly on the components and operating parameters of the system; the energy storage capacity depends on the concentration and size of the electrolytes, which greatly increases selfreliance in the energy storage system.

Flow field or bipolar plate acts as distributor of electrolyte on each half-cell in VRFB system. Due to corrosive electrolyte, graphite is often being used as bipolar plate instead of metallic. Bipolar plate is usually engraved with pattern on its surface called flow channel to thoroughly distribute the electrolyte for charge-discharge cycle. It is important to properly design the flow channel to decrease the pressure drop. Increase in pressure drop will drop the battery performance [5]. Battery performance is dependent on combination of electrode and flow field [6].

Study from Kumar et al., [1] found that the size dimensions of bipolar plate, number of channel and electrode permeability play important role in the performance of VRFB system. Several in-situ experimental researches have been reported on the role of flow field design in fuel cell and VRFB system [7-13]. The design of flow field for shift current elimination can lead to inexact design parameters, unless the effect of pressure losses can also be involved in the calculated system efficiencies [14]. Khazaeli et al., studied the effect of outlet channel width on PEM fuel cell performance and found that the narrower outlet channel width shows better performance due to uniform distribution of electrolyte [8]. C. Yin et al., developed a 3D multi-physical model of VRFB with $57.5 \mathrm{~cm}^{2}$ active area with different flow fields design and found that interdigitated flow field shows better performance than serpentine and leaf [11]. You et al., studied an active area of $900 \mathrm{~cm}^{2}$ using interdigitated flow field in RFBs whereby the study found that optimizing the number and size of channels is crucial to balance electrolyte velocity and pressure drop in electrode [12]. Zeng et al., proposed that the pumping loss of RFBs increases when scaling up to larger active area cells. That research also found that interdigitated flow field independently regulates the distribution of electrolyte thus enhancing mass transport [13]. Similarly, larger active area is found to provide smaller pressure drop as established by Darling and Perry in their study on the influence of electrode and channel configurations in flow battery [6]. Larger active area improves the peak power density, pressure drop and discharge energy [15]. On top of this, the pressure drops and mass transport study regarding the flow field in flow batteries is important to maximize the output performance. However, most of these studies focused on the comparison type of flow field design that affects the batteries' performance. Studies of flow field especially the ones that focused on the size of active area affecting VRFB performance have not been conducted systematically. In addition, review study by [27] state that right material and specification are crucial to investigate in order to keep the sustainable of a system.

The aim of present study is to compare between two active area using $5 \mathrm{~cm}^{2}$ and $25 \mathrm{~cm}^{2}$ interdigitated flow field to monitor the performance of VRFB. The optimization of flow rate, current density and volume of electrolyte will be observed to match each size of flow field.

\section{Experimental}

\subsection{Materials}

Commercial Nafion 117 with $183 \mathrm{~mm}$ thickness membrane were first pretreated with $2.0 \mathrm{M} \mathrm{H}_{2} \mathrm{SO}_{4}$ (Merck $98 \%$ ) at $100{ }^{\circ} \mathrm{C}$ for 2 hours followed by immersing the membrane in $\mathrm{H}_{2} \mathrm{O}_{2}$ (Merck 30\%) at 100 ${ }^{\circ} \mathrm{C}$ for two hours. $1.5 \mathrm{M} \mathrm{VOSO}_{4}$ in $3.0 \mathrm{M} \mathrm{H}_{2} \mathrm{SO}_{4}$ electrolyte were freshly prepared by dissolving $\mathrm{VOSO}_{4}$ (Sigma-Aldrich 97\%), SGL Graphite Felt electrode $6 \mathrm{~mm}$, Scribner single cell for redox flow battery. 


\subsection{Characterization and Measurements}

The morphology and structure of the graphite felt electrode were characterized using scanning electron microscopy (FEI Quanta 400).

\subsection{Pressure Losses in Flow Field and Porous Electrode}

The flow field of VRFB usually contains common manifolds which channel that feed electrolyte into each half-cell. The pressure losses through manifolds and channels can also be calculated on the basic of Darcy friction factor using relevant flow field design parameters. While long length and small cross-sectional area in channel and manifolds generally help lower leakage of currents, considerable pump losses are correlated with the large pressure drop in the channels which produce low system efficiencies. The appropriate arrangement between flow field and pump losses that can bring off maximum system efficiencies is thus cynical in VRFB assembly. Further to pressure losses in flow field, the porous felt electrode can cause significant pressure drops in the reaction cell. The pressure drops through a given porous felt electrode can be calculated by Darcy's equation [14]:

$\Delta p_{\text {loss }}=\frac{\mu l Q}{\kappa A}$

where $\mathrm{l}$ is the length of the porous electrode, $\mu$ is the viscosity ( $\mathrm{Pa} \mathrm{S}$ ) A is the cross-sectional area and $\mathrm{K}$ is the permeability of the porous electrode that can be decided by Kozeny-Carman equation [16]:

$\kappa=\frac{d_{f}^{2} \varepsilon^{3}}{16 K(1-\varepsilon)^{2}}$

where $d_{f}$ is the diameter of fibre, $\mathrm{K}$ is Kozeny-Carman constant and $\varepsilon$ is the porosity of the electrode $[17,18]$.

\subsection{Battery Analysis}

The study was conducted in the form of a series of experiments, with data being gathered by battery analyzer Neware BTS 4000 series. Various flow rates, current densities, and size of flow field were carried out to study the performance of battery on discharge capacity, voltage efficiency, columbic efficiency and energy efficiencies. Two sizes of interdigitated flow field were investigated in this work; $5.0 \mathrm{~cm}^{2}$ and $25 \mathrm{~cm}^{2}$.

All tests were conducted with pretreated Nafion 117 membranes [2]. The Nafion 117 membrane has thicker membrane and practical for VRFB application to slow electrolyte imbalance process [19].

All analysis was conducted with solution of $1.5 \mathrm{M}$ vanadyl sulfate in $3.0 \mathrm{M}$ sulfuric acid. The reservoir in anolyte and catholyte were filled with $40 \mathrm{~mL}$ and $80 \mathrm{~mL}$, respectively. Both solutions were charged to $100 \%$ state of charge (SOC) and then half of the electrolyte in positive side were removed so that all tests were conducted in the same volume of electrolyte. All tests were conducted at room temperature. All parameters used in this study are tabulated in Table 1. 


\section{Table 1}

Parameters of single VRFB system used in this research

\begin{tabular}{ll}
\hline Specification & Value \\
\hline No. of cells & 1 \\
Total vanadium concentration & $1.5 \mathrm{molL}^{-1}$ \\
Volume of half-cell & $30 \mathrm{~mL}$ \\
Temperature & 24 oC \\
Membrane & Nafion 117 \\
Electrode & Rayon \\
Type of flow field & Interdigitated \\
Size of flow field & $5 \mathrm{~cm}^{2}$ and $25 \mathrm{~cm}^{2}$ \\
No. of channel & 12 and 24 \\
Electrode porosity & $95 \%$ \\
Kozeny-Carman constant & 4.28 \\
Permeability of electrode & $7.04 \times 10^{-6} \mathrm{~cm}^{2}$ \\
Length of porous electrode & 2.5 and $5.0 \mathrm{~cm}^{2}$ \\
Cross-sectional area & 5 and $25 \mathrm{~cm}^{2}$ \\
Diameter of fiber & $19 \pm 0.2 \mu \mathrm{m}$ \\
\hline
\end{tabular}

\subsubsection{Discharge capacity}

The discharge capacity was determined by discharging the electrolyte solution initially at $100 \%$ SOC at a constant current until a cutoff voltage $0.8 \mathrm{~V}$ was reached. Three current densities were evaluated: $10 \mathrm{~mA} / \mathrm{cm}^{2}, 20 \mathrm{~mA} / \mathrm{cm}^{2}$ and $30 \mathrm{~mA} / \mathrm{cm}^{2}$ on two size of flow field with constant flow rate.

\subsubsection{Charge-discharge cycle}

The performance efficiencies of VRFB were determined by using charge discharge test. The charge-discharge test was conducted within a voltage range between $0.8 \mathrm{~V}$ and $1.72 \mathrm{~V}$ within 10 cycles. Based on the measurements from the single cell's charge-discharge performance, the coulombic efficiency (CE), voltage efficiency (VE) and energy efficiency (EE) can be calculated as below:

Coulumbic efficiency $=\frac{\text { Discharge capacity }(A h)}{\text { Charge capacity }(A h)}$

Voltage efficiency $=\frac{\text { Avg discharge voltage }(V)}{\text { Avg charge voltage }(V)}$

Energy efficiency $=\frac{\text { Discharge energy }(W h)}{\text { Charge energy }(W h)}$

\section{Results and Discussion}

\subsection{Discharge Capacity}

Table 2 shows results tabulation for both interdigitated flow field size during discharge of energy from VRFB. Our findings show that $25 \mathrm{~cm}^{2}$ size of flow has higher discharge capacity together with energy discharge. This indicates that the larger active area, the capacity to discharge energy increases. In line with the same operating condition found by X. D Wang et al., 2008 [20] which also agreed that the cell performance enhances gradually as the channel cross-sectional area increases. 
At this stage of understanding, the discharge capacity could be improved by conducting more study on the optimization of electrolyte and treatment of materials involved in the cycle system.

Table 2

The comparison of discharge capacity, energy discharge and time taken between $5 \mathrm{~cm}^{2}$ and $25 \mathrm{~cm}^{2}$ size of interdigitated flow field

\begin{tabular}{lllll}
\hline $\begin{array}{l}\text { Size of flow } \\
\left(\mathrm{cm}^{2}\right)\end{array}$ & $\begin{array}{l}\text { Current Density } \\
\left(\mathrm{mA} / \mathrm{cm}^{2}\right)\end{array}$ & $\begin{array}{l}\text { Discharge Capacity } \\
(\mathrm{mAh})\end{array}$ & $\begin{array}{l}\text { Energy Discharge } \\
(\mathrm{Wh})\end{array}$ & $\begin{array}{l}\text { Time taken } \\
(\mathrm{h})\end{array}$ \\
\hline 5 & 10 & 221.9 & 0.2578 & 4.27 \\
& 20 & 70.7 & 0.0747 & 1.08 \\
& 30 & 78.6 & 0.0870 & 0.39 \\
25 & 10 & 367.5 & 0.5008 & 1.28 \\
& 20 & 299.7 & 0.3925 & 0.36 \\
& 30 & 253.5 & 0.3188 & 0.20 \\
\hline
\end{tabular}

The discharge capacity decreases with the increase of the current density as shown in Figure 1. This result proves that energy density decreases when current density increases and power density increases as mentioned by Sangwon Kim [21]. This appears to be the case where decrease in energy density will increase the power density, thus it will lower the energy discharge from the battery. This is due to the stronger polarization effects derived from large current density point to low discharge capacities. These findings specify that discharge capacities are increased by lowered the current densities which cause fading acceleration for the discharge capacities. Therefore, to increase the flow rate by increasing the current density can be considered to be equivalent for large scale battery that requires high current density.

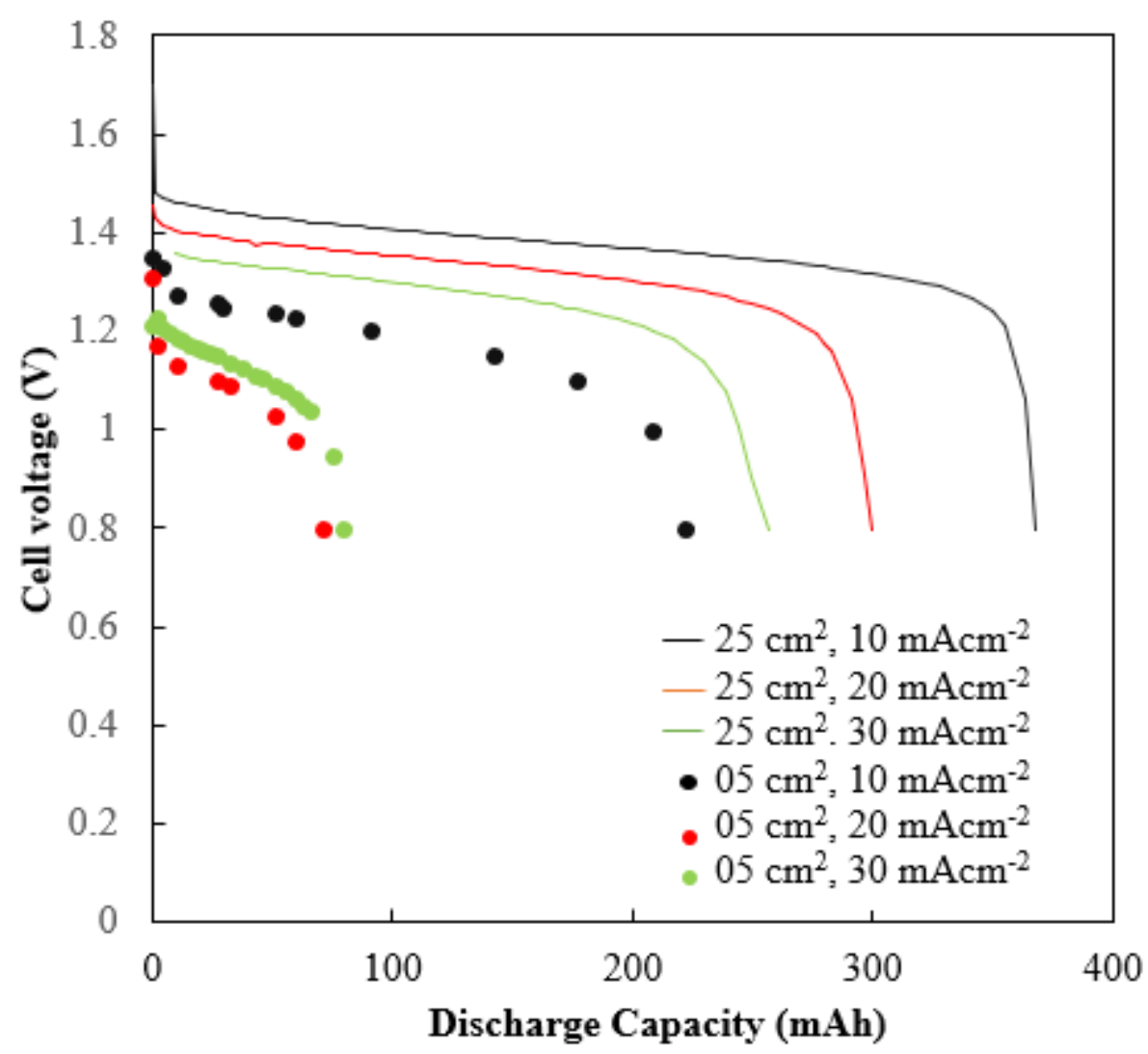

Fig. 1. Discharge curve of $5 \mathrm{~cm}^{2}$ and $25 \mathrm{~cm}^{2}$ at different current density 


\subsection{Effects of Flow Rate}

The flow field introduces an adjacent to the electrode in VRFB system as a direct path to reduce the pressure drop. The pumping system is needed for continuous flow of electrolyte during chargedischarge cycle in VRFB. Figure 2 shows the efficiencies of VRFB with different size of flow field.
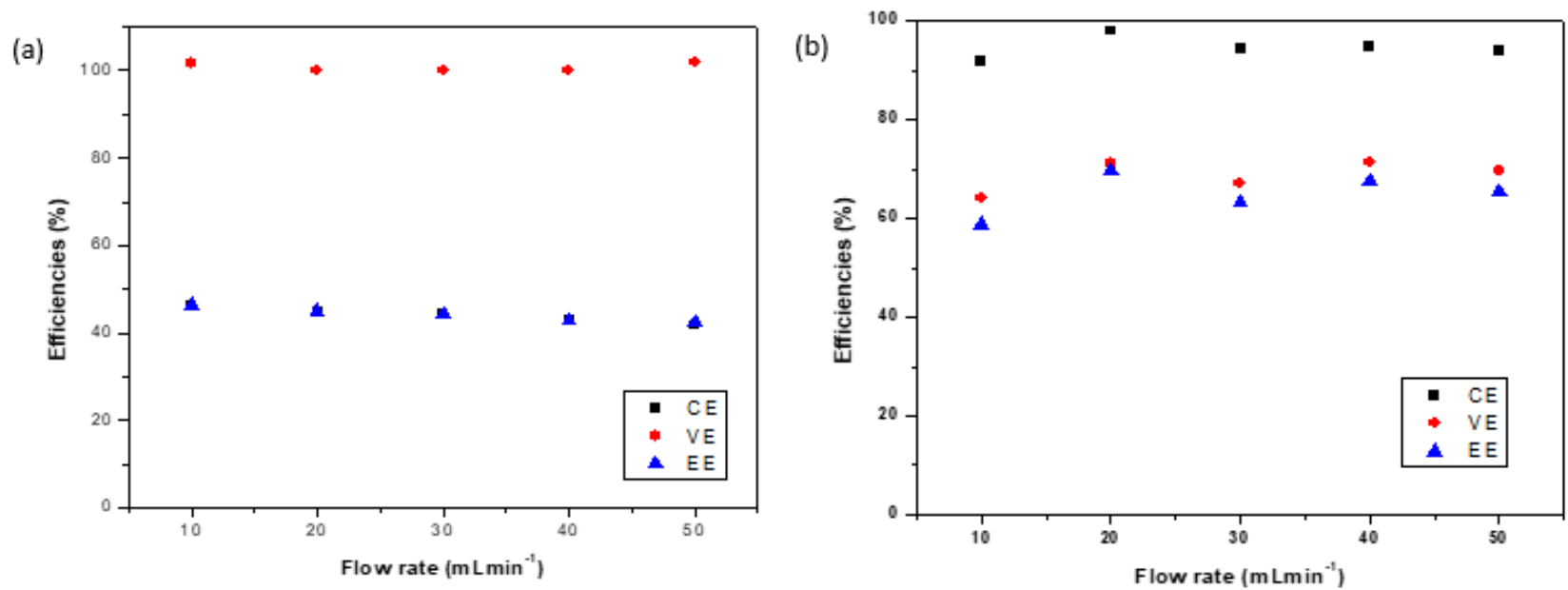

Fig. 2. Effects of flow rate on the efficiencies of VRFB (a) $5 \mathrm{~cm}^{2}$ size of interdigitated flow field (b) $25 \mathrm{~cm}^{2}$ size of interdigitated flow field (all efficiencies are at average of 10 cycles, temperature:24으. $30 \mathrm{mAcm}^{-2}$ of current density, $30 \mathrm{~mL}$ volume of electrolyte)

The optimum flow rate for $5 \mathrm{~cm}^{2}$ is at $10 \mathrm{mLmin}^{-1}, 25 \mathrm{~cm}^{2}$ flow field is $20 \mathrm{mLmin}^{-1}$ that give the highest performance efficiencies of the cell. From the graph, $25 \mathrm{~cm}^{2}$ active area has higher columbic efficiencies and voltage efficiencies than $5 \mathrm{~cm}^{2}$ active area at about $\sim 20 \%$ differences. This trend is similar with study from Y. Zeng et al., [13] which found that the section area of $5 \mathrm{~mm}^{2}$ has higher performance than $1.0 \mathrm{~mm}^{2}$ of conventional flow field channel. This is due to higher active area lowers the pressure drop in flow channel. On the other hand, $5 \mathrm{~cm}^{2}$ size of flow field shows increase in columbic efficiency when flow rate increases but both voltage efficiency and energy efficiency perform low below $60 \%$. Increasing flow rate raises the cell voltage and depth of discharge [8]. In this case, flow rate and current density are directly proportional to each other. Hence, to use higher flow rate, the increase of current density is needed too.

\subsection{Effects of Current Density}

Figure 3 shows that $5 \mathrm{~cm}^{2}$ size of interdigitated flow field best works at $40 \mathrm{mAcm}^{-2}$ current density with highest columbic efficiency. Both voltage efficiency and energy efficiency are optimum around $70 \%$, whereas $25 \mathrm{~cm}^{2}$ size of interdigitated flow field shows that highest energy efficiencies operate at low current density of $10 \mathrm{mAcm}^{-2}$. The bigger size of flow field can be operating at higher current density parallel with increasing the flow rate. For $5 \mathrm{~cm}^{2}$ size of flow field, the columbic efficiency increases by increasing the current density. 

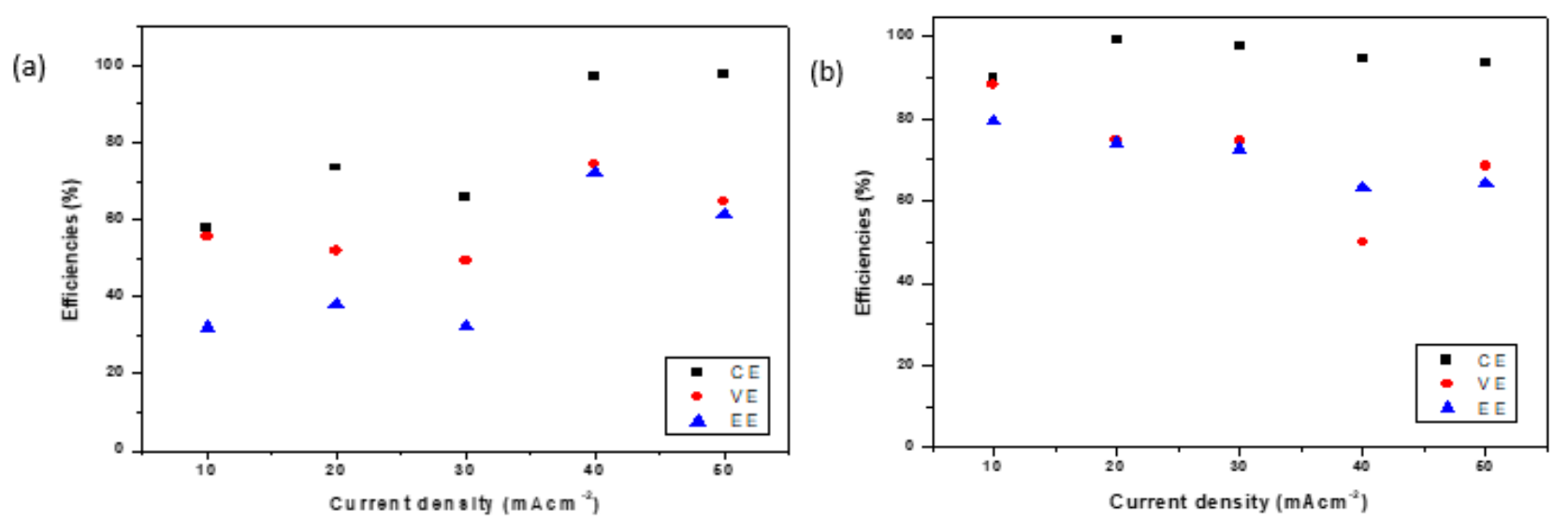

Fig. 3. The effect of the current density on the battery performance (a) $5 \mathrm{~cm}^{2}$ size of interdigitated flow field (b) $25 \mathrm{~cm}^{2}$ size of interdigitated flow field (all efficiencies are at average of 10 cycles, temperature:24으, $30 \mathrm{mLmin}^{-1}, 30 \mathrm{~mL}$ volume of electrolyte).

The same trend shows in the research by Mohamed et al., [22] indicating an improved chargedischarge cycle at higher current density. For $25 \mathrm{~cm}^{2}$, the voltage efficiency drops slightly as the current density increases from $10 \mathrm{mAcm}^{-2}$ to $40 \mathrm{mAcm}^{-2}$. This is due to the internal resistance drop during discharge of energy. The internal resistance of chemical batteries like VRFBs is typically due to the resistance of the electrolytic system. These findings conclude that bigger size of flow field might suffer from the precipitate occurs at the graphite felt. This causes some blockage for the electrolyte to freely flow as further discuss in section 3.5. As for $5 \mathrm{~cm}^{2}$ smaller size, the flow of electrolytic is quite different as the pressure is higher, lead to low internal resistance. The overall energy efficiency is more than $85 \%$ for both size at 40 and $50 \mathrm{mAcm}^{-2}$ current density, and it is comparable to other studies for VRFB systems $[22,23]$. One limitation of these findings however is that the current density is not able to achieve $80 \mathrm{mAcm}^{-2}$. This is particularly important when investigating the power generated because high current density is needed for fast charging the bigger scale of battery. The upscaling work can be investigating to increase the current density for the batteries.

\subsection{Effects Volume of Electrolyte}

The volume of electrolyte was tested on $5 \mathrm{~cm}^{2}$ size of interdigitated flow field as the current density and flow rate did not give significant effect to the optimum battery efficiency. From Figure 4, it shows that low volume of electrolyte is suitable to operate in smaller size of flow field. The highest columbic efficiency was achieved with voltage efficiency and energy efficiency around $60 \%$ of battery performance. This study is new to this research area, where most of research identified the effects of the concentration of electrolyte and state of charge of the electrolyte. Thus, this finding will be an added knowledge on the electrolyte used for VRFB system.

The electrolyte is the medium where the energy has been stored. Low volume of electrolyte indicates that only small energy can be stored. Thus, smaller size is not preferable to operate for upscaling the VRFB system. 
(a)

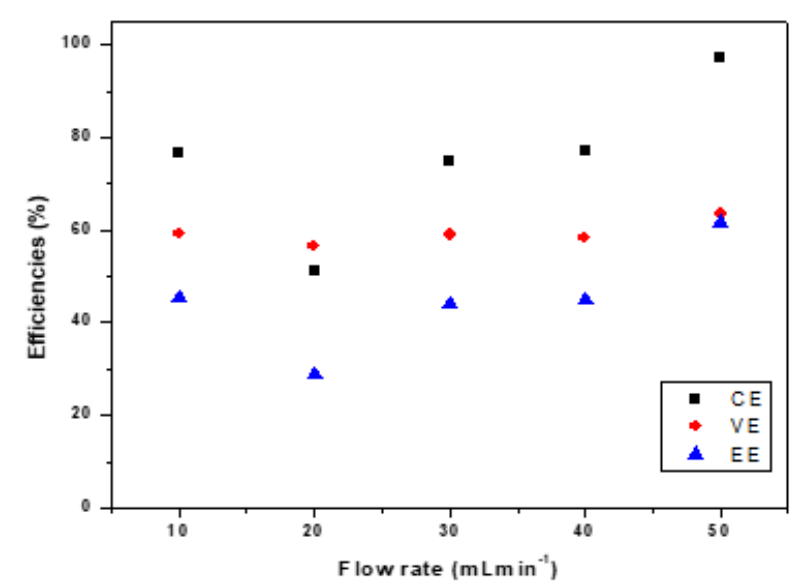

(b)

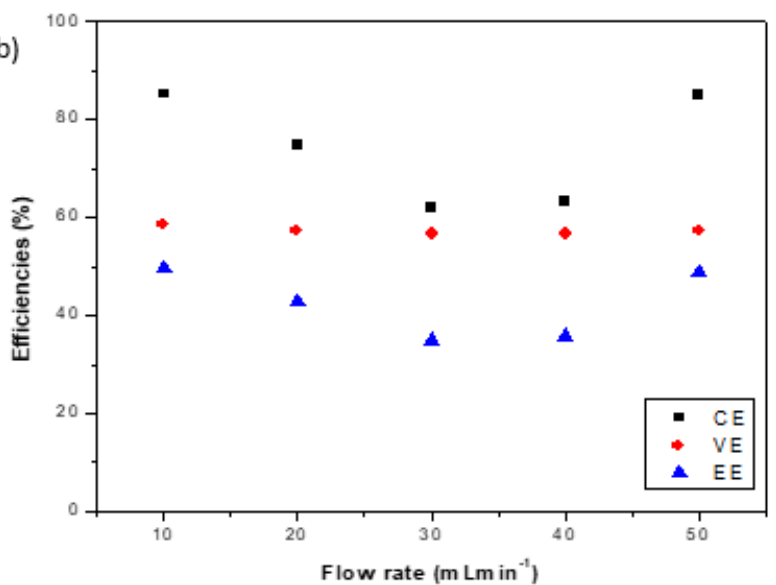

Fig. 4. Effects of volume of electrolyte on the efficiencies of VRFB (a) $10 \mathrm{~mL}$ of electrolyte on $20 \mathrm{mAcm}^{-2}$ with different flow rate (b) $50 \mathrm{~mL}$ of electrolyte on $20 \mathrm{mAcm}^{-2}$ with different flow rate (all efficiencies are at average of 10 cycles, temperature: $240 \mathrm{C}, 5 \mathrm{~cm}^{2}$ size of flow field)

\subsection{Pressure Losses in Flow Frame and Porous Electrode}

Pressure losses are tightly related to energy losses in the system. Figure 5 illustrates the increasing flow rate in each flow field that produce additional pressure losses to reduce the mass transport differences. The pressure loss at $50 \mathrm{mLmin}^{-1}$ flow rates shows significant differences between $5 \mathrm{~cm}^{2}$ and $25 \mathrm{~cm}^{2}$ size of flow field. The bigger size of flow field shows lower pressure losses than the smaller size while increasing the flow rate. This result leads to similar conclusion as reported in $[14,19]$. The same condition appears in [26], the study affirmed the pressure loss increased with smaller area. The resistance to flow affects the overall system efficiencies [28]. Hence, the suitable size of flow field is important to ensure the performance of the VRFB is maximized.

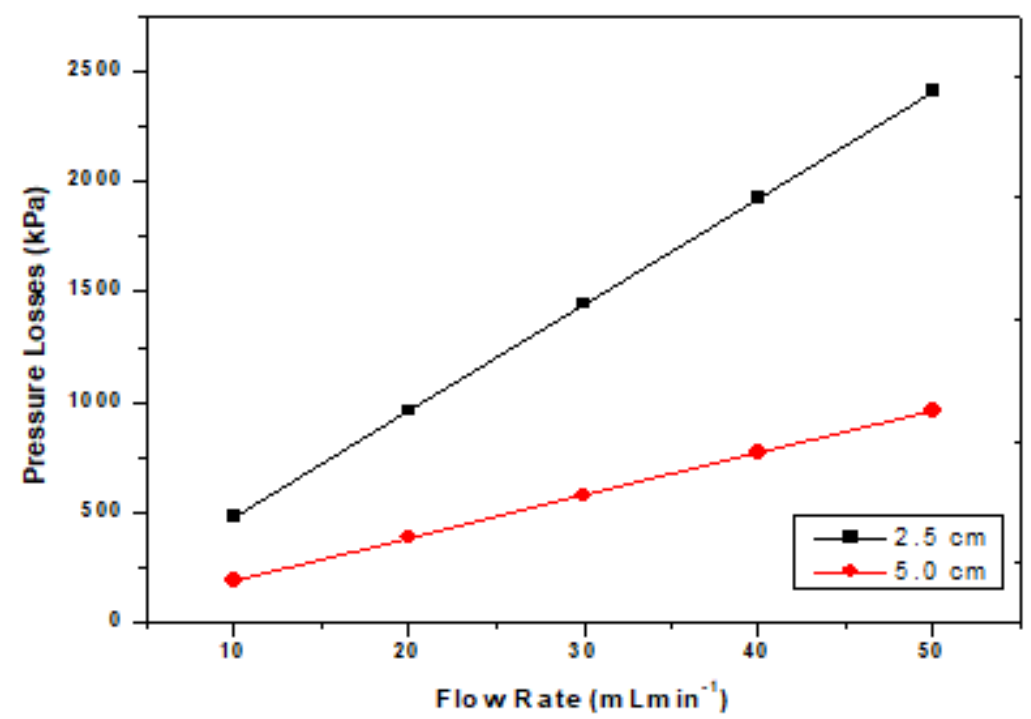

Fig. 5. Calculated pressure losses versus flow rate for $5 \mathrm{~cm}^{2}$ and $25 \mathrm{~cm}^{2}$ size of interdigitated flow field 


\subsection{SEM Results}

From the scanning electron microscopy (SEM) analysis of the graphite felt electrode, it can be seen that after 100 cycles of charge-discharge of VRFB are done, the precipitate appears on the fiber surface of porous electrode as can be seen in Figure 6 . The precipitation appeared from the deprotonation of vanadium electrolyte as it is easy to crystallize when $\mathrm{V}(\mathrm{V})$ ion reacts with $\mathrm{SO}_{4}{ }^{2-}$ complexes [24]. Unlike V(V) ion, V(II), V(III), and V(IV) ions are prone to precipitate as sulfates at low temperature [25]. The pump efficiencies can get affected with the resistance of electrolyte while the viscosity of electrolyte will influence the rate of distribution of electrolyte in the VRFB system. The stability of electrolyte in VRFB system can be further investigated to overcome this limitation.
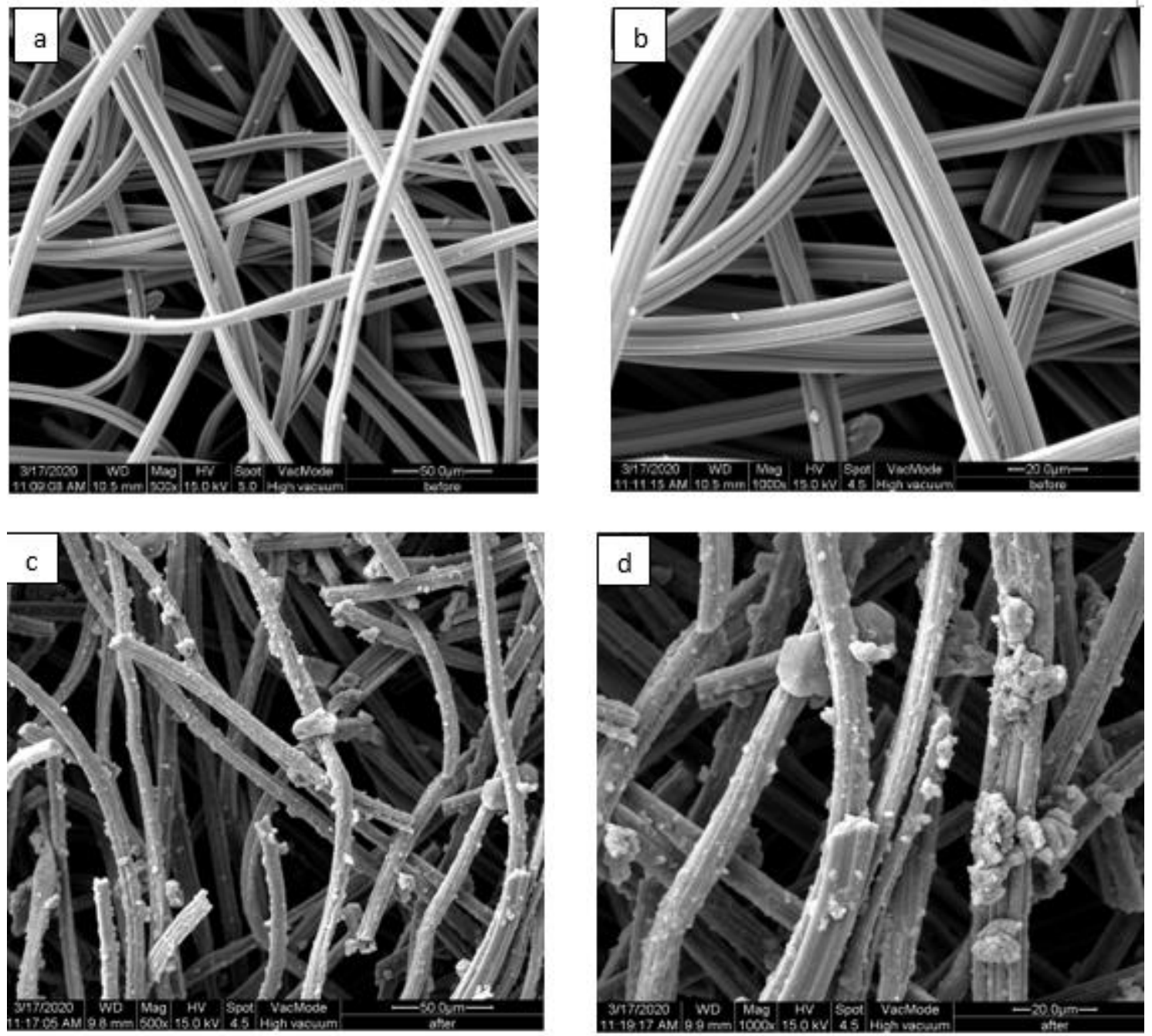

Fig. 6. SEM image of graphite felt electrode used in single cell VRFB (a) and (b) before used in VRFB (c) and (d) after 100 cycle at $50 \mathrm{mAcm}^{-2}$ in VRFB

\section{Conclusion}

A significant study of single cell of interdigitated flow field dimensions on a cell active area of about $5 \mathrm{~cm}^{2}$ and $25 \mathrm{~cm}^{2}$ has been performed. The measured parameters included the flow rate, current density, volume of electrolyte, evaluating the performance of the cell and characterization of the graphite felt electrode. The following conclusions can be drawn from these studies: 
i. $\quad 25 \mathrm{~cm}^{2}$ size of interdigitated flow field is preferable to operate in VRFB than $5 \mathrm{~cm}^{2}$ as the optimum performance of the battery is achieved.

ii. $\quad 25 \mathrm{~cm}^{2}$ size of interdigitated flow field capable to discharge energy more than $5 \mathrm{~cm}^{2}$ due to larger active area.

iii. Higher flow rate of $50 \mathrm{mlmin}^{-1}$ increased the voltage efficiencies up to $98 \%$ for $5 \mathrm{~cm}^{2}$ size of interdigitated flow field and lowest flow rate of $20 \mathrm{~mL} \mathrm{~min}^{-1}$ for $25 \mathrm{~cm}^{2}$.

iv. The current density for $5 \mathrm{~cm}^{2}$ size of interdigitated flow field for optimum efficiencies is $40 \mathrm{mAcm}^{-2}$ whereas for $25 \mathrm{~cm}^{2}$ is $10 \mathrm{mAcm}^{-2}$.

v. The pressure losses of $25 \mathrm{~cm}^{2}$ size of flow field is 3 times lower than $5 \mathrm{~cm}^{2}$ for $50 \mathrm{mLmin}^{-}$

1 flow rate that will lead to better efficiencies of the batteries.

\section{Acknowledgement}

This research was funded by Ministry of Education Malaysia under FRGS grant (vote no. FRGS/1/2018/TK05/MOSTI/03/1). We also acknowledge the financial and technical supports from Malaysian Nuclear Agency.

\section{References}

[1] Kumar, S., and S. Jayanti. "Effect of flow field on the performance of an all-vanadium redox flow battery." Journal of Power Sources 307 (2016): 782-787. https://doi.org/10.1016/i.jpowsour.2016.01.048

[2] Chen, Dongyang, Shuanjin Wang, Min Xiao, and Yuezhong Meng. "Preparation and properties of sulfonated poly (fluorenyl ether ketone) membrane for vanadium redox flow battery application." Journal of Power sources 195, no. 7 (2010): 2089-2095. https://doi.org/10.1016/i.jpowsour.2009.11.010

[3] Jiang, Bo, Lantao Wu, Lihong Yu, Xinping Qiu, and Jingyu Xi. "A comparative study of Nafion series membranes for vanadium redox flow batteries." Journal of Membrane Science 510 (2016): 18-26. https://doi.org/10.1016/i.memsci.2016.03.007

[4] Noack, Jens, and Jens Tübke. "A comparison of materials and treatment of materials for vanadium redox flow battery." ECS Transactions 25, no. 35 (2010): 235.

[5] Lourenssen, Kyle, James Williams, Faraz Ahmadpour, Ryan Clemmer, and Syeda Tasnim. "Vanadium redox flow batteries: A comprehensive review." Journal of Energy Storage 25 (2019): 100844. https://doi.org/10.1016/i.est.2019.100844

[6] Darling, Robert M., and Mike L. Perry. "The influence of electrode and channel configurations on flow battery performance." Journal of The Electrochemical Society 161, no. 9 (2014): A1381. https://doi.org/10.1149/2.0941409jes

[7] Cooper, Nathanial J., Anthony D. Santamaria, Maxwell K. Becton, and Jae Wan Park. "Investigation of the performance improvement in decreasing aspect ratio interdigitated flow field PEMFCs." Energy conversion and management 136 (2017): 307-317. https://doi.org/10.1016/i.enconman.2017.01.005

[8] Khazaeli, Ali, Ali Vatani, Nassim Tahouni, and Mohammad Hassan Panjeshahi. "Numerical investigation and thermodynamic analysis of the effect of electrolyte flow rate on performance of all vanadium redox flow batteries." Journal of Power Sources 293 (2015): 599-612. https://doi.org/10.1016/i.jpowsour.2015.05.100

[9] Santamaria, Anthony D., Nathanial J. Cooper, Maxwell K. Becton, and Jae Wan Park. "Effect of channel length on interdigitated flow-field PEMFC performance: A computational and experimental study." International journal of hydrogen energy 38, no. 36 (2013): 16253-16263. https://doi.org/10.1016/i.ijhydene.2013.09.081

[10] Wang, Lin, and Hongtan Liu. "Performance studies of PEM fuel cells with interdigitated flow fields." Journal of Power Sources 134, no. 2 (2004): 185-196. https://doi.org/10.1016/j.jpowsour.2004.03.055

[11] Yin, Cong, Yan Gao, Guangyou Xie, Ting Li, and Hao Tang. "Three dimensional multi-physical modeling study of interdigitated flow field in porous electrode for vanadium redox flow battery." Journal of Power Sources 438 (2019): 227023. https://doi.org/10.1016/j.jpowsour.2019.227023

[12] You, Xin, Qiang Ye, and Ping Cheng. "Scale-up of high power density redox flow batteries by introducing interdigitated flow fields." International Communications in Heat and Mass Transfer 75 (2016): 7-12. https://doi.org/10.1016/i.icheatmasstransfer.2016.03.021

[13] Zeng, Yikai, Fenghao Li, Fei Lu, Xuelong Zhou, Yanping Yuan, Xiaoling Cao, and Bo Xiang. "A hierarchical interdigitated flow field design for scale-up of high-performance redox flow batteries." Applied energy 238 (2019): 435-441. https://doi.org/10.1016/i.apenergy.2019.01.107 
[14] Tang, Ao, Jie Bao, and Maria Skyllas-Kazacos. "Studies on pressure losses and flow rate optimization in vanadium redox flow battery." Journal of power sources $248 \quad$ (2014): $154-162$. https://doi.org/10.1016/i.jpowsour.2013.09.071

[15] Gundlapalli, Ravendra, and Sreenivas Jayanti. "Effect of channel dimensions of serpentine flow fields on the performance of a vanadium redox flow battery." Journal of Energy Storage 23 (2019): 148-158. https://doi.org/10.1016/i.est.2019.03.014

[16] Ma, Xiangkun, Huamin Zhang, and Feng Xing. "A three-dimensional model for negative half cell of the vanadium redox flow battery." Electrochimica Acta 58 (2011): 238-246. https://doi.org/10.1016/i.electacta.2011.09.042

[17] Ding, Liming, Xipeng Song, Lihua Wang, and Zhiping Zhao. "Enhancing proton conductivity of polybenzimidazole membranes by introducing sulfonate for vanadium redox flow batteries applications." Journal of Membrane Science 578 (2019): 126-135. https://doi.org/10.1016/i.memsci.2019.02.050

[18] Liu, Bo, Yuxia Zhang, Yunhu Jiang, Penghua Qian, and Haifeng Shi. "High performance acid-base composite membranes from sulfonated polysulfone containing graphitic carbon nitride nanosheets for vanadium redox flow battery." Journal of Membrane Science 591 (2019): 117332. https://doi.org/10.1016/i.memsci.2019.117332

[19] Houser, Jacob, Jason Clement, Alan Pezeshki, and Matthew M. Mench. "Influence of architecture and material properties on vanadium redox flow battery performance." Journal of Power Sources 302 (2016): 369-377. https://doi.org/10.1016/j.jpowsour.2015.09.095

[20] Wang, Xiao-Dong, Yuan-Yuan Duan, Wei-Mon Yan, and Xiao-Feng Peng. "Effects of flow channel geometry on cell performance for PEM fuel cells with parallel and interdigitated flow fields." Electrochimica Acta 53, no. 16 (2008): 5334-5343. https://doi.org/10.1016/i.electacta.2008.02.095

[21] Kim, Sangwon. "Vanadium redox flow batteries: electrochemical engineering." Energy Storage Devices (2019): 119. https://doi.org/10.5772/intechopen.85166

[22] Mohamed, M. R., P. K. Leung, and M. H. Sulaiman. "Performance characterization of a vanadium redox flow battery at different operating parameters under a standardized test-bed system." Applied energy 137 (2015): $402-412$. https://doi.org/10.1016/i.apenergy.2014.10.042

[23] Maurya, Sandip, Phong Thanh Nguyen, Yu Seung Kim, Qinjun Kang, and Rangachary Mukundan. "Effect of flow field geometry on operating current density, capacity and performance of vanadium redox flow battery." Journal of Power Sources 404 (2018): 20-27. https://doi.org/10.1016/i.jpowsour.2018.09.093

[24] Cao, Liuyue, Maria Skyllas-Kazacos, Chris Menictas, and Jens Noack. "A review of electrolyte additives and impurities in vanadium redox flow batteries." Journal of energy chemistry 27, no. 5 (2018): 1269-1291. https://doi.org/10.1016/i.jechem.2018.04.007

[25] Yang, Yadong, Yimin Zhang, Li Tang, Tao Liu, Sui Peng, and Xiao Yang. "Improved energy density and temperature range of vanadium redox flow battery by controlling the state of charge of positive electrolyte." Journal of Power Sources 450 (2020): 227675. https://doi.org/10.1016/j.jpowsour.2019.227675

[26] Phu, Nguyen Minh, Pham Ba Thao, and Duong Cong Truyen. "Heat and Fluid Flow Characteristics of Nanofluid in A Channel Baffled Opposite to The Heated Wall." CFD Letters 13, no. 1 (2021): 33-44. https://doi.org/10.37934/cfdl.13.1.3344

[27] Mohamed, F., M. Jamil, and M. F. M. Zain. "Sustainable Material: Challenges and Prospect." Journal of Advanced Research in Materials Science 57, no. 1 (2019): 7-18.

[28] Ewis, Karem Mahmoud. "Effects of Variable Thermal Conductivity and Grashof Number on Non-Darcian Natural Convection Flow of Viscoelastic Fluids with Non Linear Radiation and Dissipations." Journal of Advanced Research in Applied Sciences and Engineering Technology 22, no. 1 (2021): 69-80. 